\title{
REGIOSELECTIVE AND HIGH-YIELDING BROMINATION OF PHENOLS AND ANILINS USING $N$-BROMOSACCHARIN AND AMBERLYST-15
}

\author{
BAHARFAR. R, ${ }^{I^{*}}$ ALINEZHAD. H, AZIMI. S, SALEHIAN. F \\ Faculty of Chemistry, University of Mazandaran, Babolsar, Iran \\ (Received: December 17, 2010 - Accepted: April 7, 2011)
}

\begin{abstract}
A regioselective and facile conversion method for bromination of anilines and phenols using $N$-bromosaccharine in the presence of a catalytic amount of Amberlyst-15 lead to enhancement of the reaction rate and yielded brominated products in good to excellent yields and short reaction times.
\end{abstract}

Keywords: Bromination; phenols; anilines; $N$-bromosaccharin; amberlyst-15.

\section{INTRODUCTION}

Bromination of aromatic compounds is a fundamentally important synthetic transformation. Brominated arenes are extensively used as precursors in the preparation of various bioactive molecules, pharmaceuticals and play vital roles in the metal catalyzed coupling reactions ${ }^{1-6} \mathrm{~A}$ variety of brominating agents are available, ${ }^{7}$ and recent reports describe the use of NBS-sulfonic acid functionalized silica, ${ }^{8} \mathrm{NBS}-\mathrm{Al}_{2} \mathrm{O}_{3},{ }^{9} \mathrm{NBS}-\mathrm{NH}_{4} \mathrm{OAc},{ }^{10} \mathrm{NBS}-\mathrm{Pd}(\mathrm{OAc}){ }_{2},{ }^{11} \mathrm{NBS}-$ DMF (or THF), ${ }^{12} \mathrm{KBr}$-benzyltriphenyl phosphonium peroxy monosulfate and peroxodisulfate, ${ }^{13,14} \mathrm{ZrBr}_{4}$-diazene, ${ }^{15} \mathrm{NBS}-\mathrm{PTSA},{ }^{16}$ bromodichloroisocyanuric acid, ${ }^{17}$ and $N$-methylpyrrolidin-2-one hydrotribromide- $\mathrm{H}_{2} \mathrm{O}_{2} \cdot{ }^{18}$

Although most of these methods provide good yields, many of them suffer from one or more disadvantages. $\mathrm{In}_{2} \mathrm{O}_{2}-\mathrm{HBr}$, the classical direct bromination of aromatic compounds ${ }^{19} \mathrm{HBr}$ is highly toxic, corrosive and as harmful as of molecular bromine to the environment. Also NBS- $\mathrm{H}_{2} \mathrm{SO}_{4}-\mathrm{H}_{2} \mathrm{O}$ system has been reported for the bromination of benzene and toluene. ${ }^{20}$ This method is unsuitable for industrial bromination of aromatic compounds due to need for stoichiometric amount of catalyst during the reaction.

From the green chemistry point of view, the replacement of such harmful reagents with non-toxic, inexpensive, commercially available, non-polluting and more selective reagents is an important goal.

$N$-halosaccharin (NXSac) are more electrophile than the structurally analogue $N$-halosuccinimides (NXS) and they have received little attention in synthetic organic chemistry. ${ }^{21} \mathrm{~N}$-Bromosaccharin (NBSac) is a white powder, easy to handle and soluble in organic solvents, for example in alcohols, acetonitrile, tetrachloromethane, ethyl acetate, trichloromethane, acetone, and 1,4-dioxane. It is environmentally friendly, easy to use as oxidant ${ }^{22}$ and as halogenating agent for allylic, ${ }^{23}$ benzylic, ${ }^{23,24}$ and $\alpha$-carbonylic positions, ${ }^{24,25}$ alkenes ${ }^{26}$ and alcohols. ${ }^{27}$

Recently, we devolved the NBSac and tungestophosphoric acid for bromination of phenol and aniline derivatives. ${ }^{28}$ As part of our research on chemical transformations, we here report an effective method for bromination of phenol, aniline and their derivatives by NBSac in the presence of Amberlyst-15 in THF at $0{ }^{\circ} \mathrm{C}$ (Scheme 1$)$.

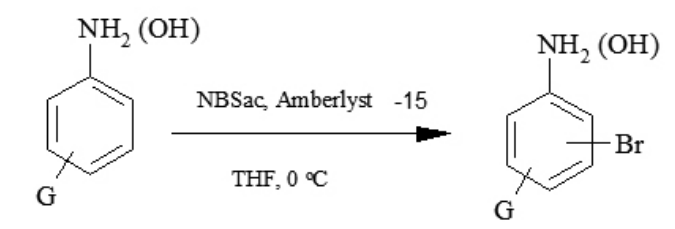

$\mathrm{G}=\mathrm{NH}_{2}, \mathrm{OH}, \mathrm{Br}, \mathrm{NO}_{2}, \mathrm{OCH}_{3}, \mathrm{Cl}, \mathrm{CH}_{3}, \mathrm{CHO}, \mathrm{CN}, \mathrm{COOH}$

Scheme 1. Bromination of phenols and anilines using $N$-bromosaccharin

\section{EXPERIMENTAL}

Materials were purchased from Merck. The reactions were monitored by TLC and were identified by comparison of their spectra $\left({ }^{1} \mathrm{H}\right.$ NMR and FT-IR) and physical data with those of the authentic samples. ${ }^{1} \mathrm{H} \mathrm{NMR},{ }^{13} \mathrm{C}$
NMR spectra were recorded with Brucker DRX500 AVANCE $(500 \mathrm{MHz})$ spectrometers, using $\mathrm{CDCl}_{3}$ as solvent. IR spectra were recorded on a Pyeunicam SP 1100 spectrophotometer.

General procedure bromination of phenols and anilines using $N$-bromosaccharin

NBSac used in this study was prepared according to the literature procedure. ${ }^{29}$ To a mixture of an arene $(1 \mathrm{mmol})$ and Amberlyst-15 $(15 \mathrm{mg}, 7$ mol\%) in THF $(5 \mathrm{~mL})$, NBSac $(1 \mathrm{mmol})$ was added. The mixture was stirred at ice bath and the reaction was followed by TLC and GC. After completion of the reaction, the mixture was filtered. The filtrate was concentrated and the residue was subjected to column chromatography (silica gel, $n$-hexane:EtOAc; $4: 1$ ) to obtain pure brominated arene.

\section{RESULTS AND DISCUSSION}

First, we selected phenol as a model compound to optimize the reaction condition. The reaction was carried out with an equimolar ratio of phenol and NBSac in the presence of Amberlyst-15 $(7 \mathrm{~mol} \%)$ at $0{ }^{\circ} \mathrm{C}$. We examined the effect of different solvents (THF, $\mathrm{CH}_{3} \mathrm{CN}, \mathrm{CH}_{2} \mathrm{Cl}_{2}, \mathrm{Et}_{2} \mathrm{O}$, EtOH) using NBSacAmberlyst-15. THF was the best solvent (Table 1). Then we examined the effect of different molar ratio of phenol: $N$-bromosaccharin in the presence of Amberlyst-15 in THF at ice bath for this conversion. We found that the optimized molar ratio was 1:1 (Table 2).

Table 1 Effect of solvents on the bromination of phenol ${ }^{\mathrm{a}}$

\begin{tabular}{|c|c|c|c|}
\hline Entry & Solvent & Time & Conversion (\%) \\
\hline 1 & $\mathrm{THF}$ & Immediately & 100 \\
2 & $\mathrm{CH}_{3} \mathrm{CN}$ & Immediately & 100 \\
3 & $\mathrm{CH}_{2} \mathrm{Cl}$ & $1 \mathrm{~h}$ & 40 \\
4 & $\mathrm{Et}_{2} \mathrm{O}$ & $1 \mathrm{~h}$ & 50 \\
5 & $\mathrm{EtOH}^{2}$ & $1 \mathrm{~h}$ & 0 \\
\hline \multicolumn{2}{|c|}{ aReaction conditions: Phenol (1mmol), NBSac (1 mmol), Amberlyst-15 (7 }
\end{tabular}
$\mathrm{mol} \%), 0{ }^{\circ} \mathrm{C}$, Solvent.

Table 2 Ratio of reagent to phenol in bromination of phenol ${ }^{\mathrm{a}}$

\begin{tabular}{|c|c|c|c|}
\hline Entry & Ratio of reagent to phenol (mmol) & Time (min) & Yield (\%) \\
\hline 1 & $1: 2$ & Immediately & 90 \\
\hline 2 & $1: 1$ & Immediately & 91 \\
\hline 3 & $1: 0.75$ & 10 & 90 \\
\hline 4 & $1: 0.5$ & 15 & 90 \\
\hline
\end{tabular}
THF as a solvent.

We then applied these optimal conditions for the bromination of various phenol and aniline derivatives and these transformations were successful and gave the desired products in good to excellent yields (Table 3).

As shown in Table 3, bromination of phenol possessing another hydroxyl group gave the corresponding dibromo catechole in good yield (Table 3 , entry 8 ). When we used phenol with electron withdrawing groups, mono brominated products obtained in low yields and long reaction times, therefore we changed 
the molar ratio of NBSac to substrate from 1:1 to 2:1 (Table 3, entries 9-13).

Aniline was immediately brominated at the para and ortho-positions with 1:1 ratio (Table 3, entry 15). Substituted anilines converted immediately to the corresponding mono-brominated products with excellent yields (Table 3, entries 16-23).

Methyl phenols and anilines underwent aryl bromination rather than benzylic bromination to give the corresponding brominated products; 4-bromo-2-methyl and 4-bromo-3-methyl phenol and 2-bromo-4-methylaniline (Table 3, entries 4, 5 and 16).

The merits of this procedure are reflected from the fact that it provides better yields of monobrominated aromatics in shorter reaction time as compared to the known methods using NBS as brominating agent. ${ }^{29}$

Table 3 Bromination of phenols and anilines using $N$-bromosaccharin ${ }^{\mathrm{a}}$

\begin{tabular}{|c|c|c|c|c|c|c|}
\hline Entry & Substrate & Product $^{c}$ & Time (min) & Yield d $(\%)$ & $\mathrm{MP}\left({ }^{\circ} \mathrm{C}\right)$ & Ref. \\
\hline 1 & & & Immediately & 91 & 66 & 8 \\
\hline 2 & & & 2 & 90 & $78-79$ (79.5) & 13 \\
\hline 3 & & & Immediately & 94 & $86-88(87.5)$ & 13 \\
\hline 4 & & & Immediately & 63 & $63-64(64)$ & 8 \\
\hline 5 & & & 3 & 87 & $57-61$ & 8 \\
\hline 6 & & & Immediately & 70 & 88 & 31 \\
\hline 7 & & & Immediately & 72 & 165 & 31 \\
\hline 8 & & & Immediately & 89 & 122 & 32 \\
\hline $9^{b}$ & & & 8 & 98 & 40 & 33 \\
\hline $10^{\mathrm{b}}$ & & & Immediately & 95 & 126 & 34 \\
\hline $11^{\mathrm{b}}$ & & & Immediately & 90 & 172 & 35 \\
\hline $12^{\mathrm{b}}$ & & & 5 & 84 & 114 & 30 \\
\hline $13^{\mathrm{b}}$ & & & 10 & 95 & 92 & 31 \\
\hline 14 & & & 2 & 98 & 82 & 8 \\
\hline \multirow{2}{*}{15} & & & \multirow{2}{*}{ Immediately } & 50 & 30 & \multirow{2}{*}{8} \\
\hline & & & & 50 & 64 & \\
\hline 16 & & & Immediately & 88 & 26 & 8 \\
\hline
\end{tabular}




\begin{tabular}{|l|l|l|l|l|l|}
\hline & & & & \\
\hline
\end{tabular}

${ }^{a}$ All reactions were carried out at $0{ }^{\circ} \mathrm{C}$, and the molar ratio of reagent:phenol or aniline was 1:1.

${ }^{\mathrm{b}}$ The molar ratio of reagent:phenol was $2: 1$.

${ }^{\mathrm{c}}$ All products were characterized spectroscopically $\left({ }^{1} \mathrm{H}\right.$ NMR , IR), and showed physical and spectral data in accordance with their expected structure and by comparison with authentic samples.

${ }^{\mathrm{d} Y i e l d}$ refers to pure isolated product.

\section{CONCLUSION}

In conclusion, we have developed an efficient, versatile, selective and general method for the bromination of phenols and anilines using easily prepared NBSac in the presence of catalytic amount of amberlyst- 15. pared NBSac in the presence of catalytic amount of amberlyst- 15.
The mild reaction conditions, rapid conversion, good to excellent yields,
16.- P. Bovonsomb

high regioselectivity and reusability of the catalyst are advantages of this 17.- L. S. De Almeida, P. M. Esteves, M. C. S. De Mattos. Synlett 1687 , protocol.

\section{ACKNOWLEDGMENTS}

We are thankful to the Research Council of University of Mazandaran for the partial support of this work.

\section{REFERENCES}

1.- C. Chrisophersen, Acta Chem. Scand. 39, 517, (1985).

2.- D. B. Boyd, Ulmann's Encyclopedia of Industrial Chemistry, sixth ed., Wiley, Weinheim (1998).

3.- J. K. Still, Pure Appl. Chem. 57, 1771, (1985).

4.- N. Miyauro, A. Suzuki, Chem. Rev. 95, 2457, (1995).

5.- I. P. Beletskaya, A.V. Cheprakov, Chem. Rev. 100, 3009, (2000).

6.- W. Cabri, I. Canadiani, Acc. Chem. Res. 28, 2, (1995).

7.- (a) M. B. Smith, J. March, March's Advanced Organic Chemistry: Reactions, Mechanisms, and Structure, 6th ed.; Wiley: New York, 698, (2007); (b) R. C. Larock, Comprehensive Organic Transformations, 2nd ed.; Wiley-VCH: New- York, 622, (1999).

8.- B. Das, K. Venkateswarlu, M. Krishnaiah, H. Holla, Tetrahedron Lett. 47, 8693, (2006).

9.- G. K. Imanzadeh, M. R. Zamanloo, H. Eskandari, K. Shayesteh, J. Chem Res. (S), 151, (2006).

10.- B. Das, K. Venkateswarlu, A. Majhi, V. Siddaiah, K. R Reddy, J. Mol Catal. A: Chem., 267, 30, (2007).

11.- (a) D. Kalyani, A. R. Dick, W. Q. Anani, M. S. Sanford, Org. Lett (2006), 12, 2523; (b) D. Kalyani, A. R. Dick, Anani, W. Q. M. S. Sanford, Tetrahedron 62, 11483, (2006).

12.- D. Pla, F. Albericio, M. Alvarez, Eur. J. Org. Chem. 1921, (2007).
13.-H. Adibi A. R, Hajipour, M. Hashemi, Tetrahedron Lett. 48, 1255, (2007).

14.- H. Tajik, I. Mohammadpoor-Baltork, J. Albadi, Synth. Commun. 37, 323, (2007).

5.- T. Stropnik, S. Bombek, M. Kocevar, S. Polanc, Tetrahedron Lett. 49, (2007).

18.- S. Singhal, S. L. Jain, B. J. Sain, Mol. Catal. A: Chem. 258, 198, (2006).

19.- N. B. Barhate, A. S. Gajare, R. D. Wakharkar, A. V. Bedekar, Tetrahedron Lett. 39, 6349, (1998).

20.- F. L. Lambert, W. D. Ellis, R. J. Parry, J. Org. Chem. 30, 304, (1965).

21.- D. Dolenc, Synlett, 544, (2000).

22.- (a) J. M. Bachhawat, N. K. Mathur, Indian J. Chem. 9, 1335, (1971); (b) V. Manoharan, N. Venkatasubramanian, J. Indian Chem. Soc. 63, 613, (1986).

23.- J. M. Bachhawat, A. K. Koul, B. Prashad, N. S. Ramegowda, C. K. Narang, N. K. Mathur, Indian J. Chem. 11, 609, (1973).

24.- E. I. Sanchez, M. J. Fumarola, J. Org. Chem. 47, 1588, (1982).

25.- V. S. Panchatsharam, S. Sundaram, N. Venkatasubramanian, Indian J. Chem., 20A, 469 (1981).

26.- M. C. S. De mattos, S. P. L De souza, J. F. M. De Silvia, J. Braz. Chem. Soc. 14, 5, (2003).

27.- H. Firouzabadi, N. Iranpoor, F. Ebrahimzadeh, Tetrahedron Lett. 47, 1771, (2006).

28.- H. Alinezhad, S. Mohseni Tavakkoli, F. Salehian, Synth. Commun. 40, 3226, (2010).

29.- S. P. L De Souza, J. F. M. Da Silva, M. C. S. De Mattos. Synth. Commun. 33, 935, (2003).

30.- P. K. Chhattise, A. V. Ramasawamy, S. B. Waghmode, Tetrahedron Lett. $49,189,(2008)$.

31.- S. Mallick, K. M. Parida, Catal. Commun. 8, 889, (2007)

32.- J. Frejka, B. Sefranek, Collect. Czech. Chem. Commun.8, 130, (1936).

33.- T, Hashimoto, J. Pharm. Soc. Jpn., 80, 1399, (1960).

34.- H. H. Hodgson, H. G. Berrd, J. Chem. Soc. 875, (1925).

35.- O. S. Tee, M. Paventi, J. M. Bennett. J. Am. Chem. Soc. 111, 2233, 989 , (1989). 